Revista Destaques Acadêmicos, Lajeado, v. 11, n. 1, 2019. ISSN 2176-3070

DOI: http://dx.doi.org/10.22410/issn.2176-3070.v11i1a2019.1982

http://www.univates.br/revistas

\title{
INOVAÇÃO TECNOLÓGICA E OS DESAFIOS PARA UMA CONTABILIDADE INTERATIVA: ESTUDO DOS ESCRITÓRIOS DE CONTABILIDADE DO ESTADO DE SANTA CATARINA
}

\author{
Cilda Giese da Silva ${ }^{1}$, Marino Luiz Eyerkaufer ${ }^{2}$, Rodrigo Rengel ${ }^{3}$
}

\begin{abstract}
Resumo: O objetivo deste estudo consiste na identificação dos desafios para a contabilidade interativa diante dos avanços tecnológicos, observando os escritórios do estado de Santa Catarina. Os dados do survey revelam que a Tecnologia da Informação (TI) proporcionou a oferta de novos produtos aos seus clientes, além de informações mais ágeis e seguras o que permite maior integração de informações entre os escritórios e seus clientes. A vinda da internet foi considerada pela maioria dos respondentes como a maior inovação tecnológica para os escritórios de contabilidade, no entanto, também elevou os gastos operacionais devido à necessidade de melhorias continuas na qualidade dos serviços. A complexidade dos serviços e o aumento das tarefas com o advento da tecnologia, sem aumento no valor dos honorários, revelam que economicamente as evoluções tecnológicas não proporcionaram maior lucratividade para os escritórios. Conclui-se que os principais desafios da TI para os escritórios é fazer uso da internet para otimizar as tarefas, preparar-se diante da complexidade dos serviços exigidos, além de buscar maior interação com os clientes, ao mesmo tempo que oportunidades também podem ser vistas, a exemplo da disponibilização de novos serviços e o atendimento a novos mercados.
\end{abstract}

Palavras-chave: Inovação tecnológica; Desafios; Contabilidade interativa; Escritórios de contabilidade.

\section{INTRODUÇÃO}

Nas últimas décadas, a contabilidade vem sendo impactada pelos avanços da tecnologia, assim como os diversos setores da economia. Se por um lado estes avanços permitem maior interação, por outro lado requerem novas

1 Universidade do Estado de Santa Catarina (UDESC).

2 Universidade do Estado de Santa Catarina (UDESC).

3 Universidade Federal de Santa Catarina (UFSC). 
habilidades conceituais frente a estas inovações que afetam a dinamicidade da informação, a comunicação e, sobretudo os processos.

Tornatzky e Fleischer (1990) afirmam que inovação tecnológica não é nem um evento singular, nem um pequeno número de eventos discretos. Inovação tecnológica envolve muitos eventos, muitas atividades, muitas decisões e muitos comportamentos da parte de indivíduos e unidades sociais.

Logo, a contabilidade tem sofrido constantes mutações, não apenas legislativas, mas também práticas. Esta evolução advém da própria necessidade do mercado em receber informações cada vez mais precisas e mais rápidas para a tomada de decisões. Por conta disto, assim como a ciência, que está em constante evolução, o profissional contábil também precisa evoluir. Esta é a rotina dos contabilistas que todo o tempo precisam se atualizar e estudar assuntos correlatos à contabilidade, ao mercado financeiro, ao sistema de tributação e à tecnologia que cerca todos estes conceitos.

Segundo Zanluca (2009), ao falar do perfil do contabilista do século XXI, comenta que a principal característica da profissão, será o conhecimento aplicado. Não menos importante, é que o contabilista precisa ser um profissional flexível, autodidata e preparado para enfrentar desafios de uma profissão na qual a competição e exigências crescem a cada dia.

Lunelli (2016) relata que não é necessário voltar muito no tempo para ver as modificações que a tecnologia trouxe para os profissionais de contabilidade, poucos anos atrás, as declarações de imposto de renda eram disponibilizadas aos clientes em formulário ou disquete a ser entregue pessoalmente nos endereços da Receita Federal. Hoje, com a internet cada vez mais consolidada dentro das organizações, este processo tornou-se muito mais ágil e prático. Basicamente todas as obrigações acessórias das entidades podem ser cumpridas por meio de programas de processamento de dados que tratam as informações e as remetem ao órgão competente. É claro que com isto, a fiscalização também ganhou agilidade.

Quando se fala do perfil dos contabilistas, pode-se dizer que grande parte dos 21.567 profissionais registrados no Conselho Regional de Contabilidade de Santa Catarina (CFC, 2016), atua em escritórios de serviços contábeis, que sofrem os impactos da evolução assim como os profissionais que atuam diretamente nas organizações.

Para Barbosa (2000), o profissional contábil é um elemento que integra a organização e por isto está inserido nesse contexto de evolução. Ele vem sofrendo uma forte pressão diante das mudanças, pois a sua função está sendo reformulada a cada passo desse processo de transformação. O profissional contábil deve buscar alternativas para agregar valor não só a empresa com o seu trabalho, utilizando a Tecnologia da Informação como uma aliada na aquisição e desenvolvimento de competências. 
Diante disso, surge o problema de pesquisa: Quais são os desafios para os escritórios de contabilidade do estado de Santa Catarina para a interatividade diante da inovação tecnológica?

Para atender ao problema de pesquisa, o objetivo do estudo propõe a identificação dos desafios para a contabilidade interativa diante dos avanços tecnológicos, observando os escritórios contábeis localizados no estado de Santa Catarina.

O estudo dos desafios da interação diante dos avanços tecnológicos se justifica diante de suas contribuições científicas e sociais. Inicialmente os estudos sobre os avanços da tecnologia e seus impactos sobre os serviços dos escritórios de contabilidade não são recorrentes na literatura. Zwirtes e Alves (2014) se dedicaram a identificar os impactos causados pela inovação tecnológica, pesquisando o Estado do Rio Grande do Sul. Uma investigação baseada no estudo de Zwirtes e Alves (2014) foi realizada em Santa Catarina com o propósito de identificar os desafios da TI para os escritórios de contabilidade, considerando que se passaram três anos da realização da pesquisa e ainda as características regionais que poderão ser destacadas com os dados obtidos. As contribuições sociais do estudo se evidenciam pela importância do tema no dia a dia dos escritórios de contabilidade que vem sofrendo com a veemente necessidade de investimentos, atualização e desenvolvimento de novas habilidades diante dos avanços tecnológicos.

Apresenta-se inicialmente na primeira seção a introdução do estudo, seguido do referencial teórico na segunda seção. Na terceira seção apresentase o método de estudo e na quarta seção os dados do estudo, seguido das considerações finais na quinta seção e as referências que sustentam a discussão.

\section{REFERENCIAL TEÓRICO}

Faz-se necessário neste estudo uma fundamentação teórica, para que o tema possa ser melhor compreendido. Essa seção inicia abordando a evolução da contabilidade seguida da evolução da tecnologia da informação e a contabilidade, encerrando com o estudo sobre os impactos da tecnologia da informação e os escritórios de contabilidade.

\subsection{Evolução da contabilidade}

De acordo com a história, pode-se afirmar segundo Iudícibus (2000, p. 29) que a contabilidade é tão antiga quanto à existência humana. Alguns historiadores relembram os primeiros sinais da existência contábil aproximadamente há 4000 anos A. C. (antes de Cristo). “Entretanto, antes disto, o homem primitivo, ao inventariar o número de instrumentos de caça e pesca disponível, ao contar seus rebanhos e suas ânforas de bebidas, já estava praticando uma forma rudimentar de contabilidade" (IUDÍCIBUS, 1997. p. 30). 
Schmidt (2000, p.11) pondera que embora se tenha por costume considerar a obra "Summa de Arithmetica, Geometria, Proportioni et Proportionalita" do Frei Luca Pacioli como o nascimento da contabilidade, uma série de descobertas arqueológicas vem alterando esse pensamento, levando-os a refletir a contabilidade como advinda da era pré-histórica, juntamente com a origem das civilizações.

Segundo o professor Frederigo, autor do livro "Storia della Ragioneria" (História da Contabilidade), a história da contabilidade se divide em quatro períodos (SÓ CONTABILIDADE, 2016): (i) Contabilidade Antiga: assim chamada para o período desde as primeiras civilizações até 1202 da Era Cristã. Nesta época o autor Leonardo Fibonacci, o Pisano, escreveu o Liber Abaci; (ii) Contabilidade Medieval: período que vai de 1202 da Era Cristã até 1494 . Em 1494 o Frei Luca Pacioli publicou o "Tratactus de Computis et Scripturis" (Contabilidade por Partidas Dobradas), e a partir daí a contabilidade foi introduzida entre os ramos do conhecimento humano; (iii) Contabilidade Moderna: período que vai de 1494 até 1840. A obra"La Contabilità Applicatta alle Amministrazioni Private e Pubbliche", da autoria de Franscesco Villa, premiada pelo governo da Áustria, foi um marco na história da Contabilidade; e (iv) Contabilidade Científica: período que se inicia em 1840 e continua até os dias de hoje.

A Contabilidade vem sofrendo mudanças desde a sua existência por conta do desenvolvimento econômico, político, cultural, social, científico e pelo conhecimento adquirido com base na tentativa e erro por meio da experiência do dia-a-dia. Todo esse processo se deu por meio da contribuição de vários cientistas que foram responsáveis pela apresentação do conhecimento cientifico em contabilidade, podendo citar entre eles Francesco Villa, La Porte, Giuseppe Cerboni, Fábio Besta, Eugen Schmalenbach, Alberto Ceccherelli, Gino Zappa, Vicenzo Mais, Jaime Lopes Amorim, Francisco D'Auria, Frederico Hermann Júnior, Sérgio Iudicibus e Antônio Lopes de Sá (PIRES; MARQUES, 2007).

Franscesco Villa, em sua obra "La Contabilità Applicattaalle Amministrazioni Private e Pubbliche", extrapolou os conceitos tradicionais de Contabilidade, segundo os quais escrituração e guarda livros poderiam ser feitas por qualquer pessoa inteligente. Para ele, a Contabilidade implicava conhecer a natureza, os detalhes, as normas, as leis e as práticas que regem as matérias administradas, ou seja, o Patrimônio. Era o pensamento patrimonialista. Foi o início da fase científica da Contabilidade (SÓ CONTABILIDADE, 2016).

Frei Luca Pacioli, considerado o pai da contabilidade moderna, em seu livro "Summa de Arithmetica, Geometria, Proportioni et Proportionalità" (Conhecimentos de Aritmética, Geometria, Proporção e Proporcionalidade), enfatiza que a teoria contábil do débito e do crédito corresponde à teoria dos números positivos e negativos. Este método teve rápida difusão, sendo universalmente aceito e adotado desde esta época. Esta obra serviu pra sistematizar e popularizar a contabilidade, marcando o início da fase moderna 
da contabilidade. Na contabilidade atual, este método continua a ser usado a todo o vapor (SÓ CONTABILIDADE, 2016).

Com as constantes mudanças no contexto econômico, social, político, e na estrutura organizacional das empresas, como é o caso das empresas virtuais, a Contabilidade passa a assumir novos desafios, traduzidos pelo volume e pela complexidade das transações que envolvem as operações das empresas em geral.

Segundo relata Padovezze (2000), um dos reflexos do desenvolvimento tecnológico na Contabilidade, pode ser verificado no aumento do grau de automação. Tarefas anteriormente realizadas por processos manuais já são desenvolvidas dentro de softwares específicos, diminuindo o fluxo de papéis e documentos na empresa, um exemplo disso, são as rotinas mais frequentes que passaram a ser realizadas dentro dos sistemas, como é o caso de: lançamentos de débito e créditos, escrituração de livros fiscais, balancetes mensais, Balanço Patrimonial, Demonstração do Resultado do Exercício, entre outros.

Porém, esses sistemas somente serão eficazes, se puderem por meio dos dados condensados fornecer as informações que se esperam da realidade patrimonial. Nesse contexto, é o Contador, responsável em dar relevância aos dados que servirão de base para as informações. Contudo, apesar dos benefícios oriundos da automação nas rotinas contábeis, necessitamos avaliar alguns pontos, como por exemplo (LUNELLI, 2016): (i) Com as novas tecnologias, os sistemas apesar de fornecerem informações com precisão e rapidez, se tornam ferramentas vulneráveis ao ataque de "vírus" que podem ocasionar na perda parcial ou total dos dados, o que levaria um retrabalho por parte da contabilidade; (ii) Operar com um sistema informatizado exige uma qualificação adequada do usuário; (iii) Devido a vulnerabilidade dos sistemas, mediante a invasão de hackers ou apropriação indevida de informações por partes dos funcionários, a empresa necessita criar meios e/ou instrumentos de garantir para salvaguarda suas informações; e (iv) O crescente número de informações e usuários que utilizam as redes de computadores implica maiores custos de desenvolvimento e manutenção dos sistemas para as empresas.

Ao observar a evolução contábil, nota-se que métodos utilizados em cada período da história da contabilidade eram considerados avançados, desde os primórdios quando se contavam pedrinhas e até os últimos softwares. Podese dizer então que a evolução contábil não alcançou seu ápice ou não chegará a ele tão cedo (LUNELLI, 2016).

Segundo Hendriksen e Breda (1999, p.38):

A Contabilidade desenvolveu-se em resposta a mudanças no ambiente, novas descobertas e progressos tecnológicos. Não há motivo para crer que a Contabilidade não continue a evoluir em resposta a mudanças que estamos observando em nossos tempos. 
Corroborando com o que Hendriksen e Breda (1999) destacam em relação ao desenvolvimento da contabilidade em resposta às mudanças ambientais, faz-se necessário discutir os avanços da tecnologia da informação e a contabilidade neste contexto.

\subsection{A tecnologia da informação e a contabilidade}

Desde os primeiros registros contábeis até os dias atuais, a tecnologia, vem cada dia mais sendo inserida na execução das operações e serviços das empresas, por meio dos diversos recursos à disposição dos usuários. E é claro, a contabilidade não poderia deixar de sofrer a influência desses avanços tecnológicos.

Cornachione Jr. (2001, p.105) descreve que, "hoje não é mais possível aceitar o eficaz desempenho profissional em um amplo leque de atividades econômicas, científicas e educacionais, e mesmo esportivas, sem o apoio da informática, a contabilidade não foge à regra".

Quando Lunelli (2016) escreve que a era digital foi um dos maiores marcos da evolução contábil, e que com sistemas mais evoluídos e complexos a contabilidade passou de uma simples escrituração primitiva para uma forma rápida e eficiente de interação das informações necessárias para uma tomada de decisão mais eficaz, deixa evidente que a contabilidade deve-se atentar à essa era a fim de atender as necessidades de seus usuários, que cada vez mais precisam de informações prestadas pela contabilidade em tempo real.

Por conta dos avanços da tecnologia, a informação contábil precisa de uma resposta mais ágil diante das exigências do mercado atual, e essa evolução sugere uma mudança no perfil do profissional contábil e por sua vez dos escritórios de contabilidade (LUNELLI, 2016).

Lunelli (2016) ainda escreve que as diversas funções realizadas pela contabilidade, como escrituração, elaboração divulgação, análise e controle dos dados contábeis, foram afetadas profundamente em suas metodologias. Os procedimentos atuais utilizados na contabilidade para alcançar os seus objetivos evoluíram sobremaneira. A introdução das redes tornou possível a comunicação virtual dos contadores com os órgãos públicos, ao passo em que se verificam mudanças na composição e estrutura das organizações.

A evolução está inserida no mundo. Pode-se perceber os avanços em todas as áreas, sejam financeiras, intelectuais e tecnológicas, e a contabilidade sempre contribui de alguma forma com a evolução (LUNELLI, 2016).

\subsubsection{Impactos da tecnologia da informação e os escritórios de contabilidade}

De acordo com Suwardy et al. (2003), a área contábil foi uma das primeiras a utilizar as Tecnologias da Informação e Comunicação (TIC), em função de rotinas repetitivas e da necessidade de cálculos regulares, transformando, 
assim, os escritórios de contabilidade em indústrias de prestação de serviços (BANKER; CHANG; KAO, 2002).

Os escritórios de contabilidade, de acordo com Sá e Sá (1995), são organizações que exploram as atividades contábeis, tendo como atividade principal, conforme afirmam Fedato, Rehn e Almeida (2009), fornecer informações econômico-financeiras para os mais diversos usuários.

Essas organizações contábeis, segundo Souza (2003), contribuem significativamente para o desenvolvimento econômico do país. Contudo, esses escritórios de contabilidade dependem de melhorias contínuas em seus serviços e do desempenho dos negócios, para que possam atender seus clientes de forma mais satisfatória.

Para que esse atendimento se torne satisfatório aos seus usuários, os escritórios de contabilidade devem ir muito além da escrituração contábil (HENRIQUE ET AL., 2009), isto é, precisam aprofundar seus conhecimentos em gestão empresarial e buscar inovações que proporcionem segurança e credibilidade das informações, criando uma relação de confiança com as partes interessadas.

Observa-se através dos dados extraídos junto ao Conselho Federal de Contabilidade, que do ano 2004 ao ano 2011, houve um aumento de 35,85\% no registro de profissionais, enquanto que o registro de organizações contábeis cresceu $16,12 \%$ neste mesmo período. Esses aumentos equivalem a 128.708 novos profissionais inscritos nos Conselhos Regionais de Contabilidade e 10.963 novas organizações atuantes (CFC, 2016).

Segundo Padovezze (2000), os reflexos do desenvolvimento tecnológico na contabilidade, podem ser verificados no aumento do grau de automação. Diversas tarefas que anteriormente eram realizadas por processos manuais já são desenvolvidas dentro de softwares específicos, diminuindo o fluxo de papéis e documentos na empresa.

Há algum tempo, a tecnologia tem mudado a forma de trabalhar de todos os profissionais inclusive os de contabilidade. Já escreveu Drucker (2000, p. 48), que a utilização explosiva da internet está modificando profundamente economias, mercados e estruturas setoriais; os produtos e serviços e seu fluxo; a segmentação, os valores e o comportamento dos consumidores; o mercado de trabalho. Portanto, o impacto da internet na prática contábil é o que impulsiona os maiores avanços, pela infinita capacidade de armazenamento, como o uso de plataformas em nuvem, como a resposta rápida da informação, chamada como informação em tempo real.

A informação em tempo real e a confiabilidade dessas informações, são peças-chave para a criação de relacionamentos de confiança das organizações contábeis e seus usuários. A tecnologia deixa de ter um papel meramente operacional e passa a ser um recurso estratégico no negócio. Nesse sentido, os desafios para a contabilidade são consideráveis, desde que a necessidade de 
incorporação das novas tecnologias até a compreensão dos seus efeitos sobre a evolução do patrimônio. Paiva (2002, p.75) escreve: “Uma aliança estratégica entre a contabilidade e as novas tecnologias de informação proporcionarão as organizações condições mais seguras para tomarem decisões estratégicas proativamente".

A inovação é uma estratégia de competição eficaz e efetiva. Embora os novos produtos sejam encarados como a linha de frente da inovação no mercado, a inovação de processos desempenha um papel estratégico igualmente importante. De forma semelhante, a capacidade de prestar melhores serviços mais rápidos, mais baratos e de melhor qualidade - já é muito considerada como fonte de vantagem em competitividade (TIDD; BESSANT, 2015).

\section{PROCEDIMENTOS METODOLÓGICOS}

Trata-se de um estudo descritivo, que fez uso do método survey, com abordagem quantitativa dos dados. A pesquisa foi enviada a todas as organizações contábeis registradas no Conselho Regional de Contabilidade de Santa Catarina, para os e-mails dos responsáveis pelas organizações, diretamente do CRCSC com sede em Florianópolis, uma vez que não foi possível obter junto ao conselho a lista de contatos para o envio direto.

Pelo e-mail, foi enviado um link de acesso ao Google formulários contendo o questionário a ser respondido, sem que o respondente fosse identificado, conforme exigência do CRCSC. São 3.800 escritórios registrados, dos quais 55 responsáveis responderam ao questionário enviado.

Efetuou-se a revisão bibliográfica, na qual a pesquisa de Zwirtes e Alves (2014) demonstrou semelhança com os objetivos do estudo, o qual serviu de modelo de desenvolvimento do questionário, mais tarde aplicado para os escritórios de contabilidade do estado de Santa Catarina.

O questionário foi composto por questões que identificaram a estrutura dos escritórios, o perfil do responsável e questões diretamente relacionadas aos impactos da tecnologia na estrutura. Os dados tabulados permitem qualificar os respondentes em relação ao tamanho do escritório, anos de atuação, qualificação do responsável e equipe, e ainda identificar como os escritórios estão tratando a inserção da tecnologia nas suas atividades.

O levantamento tem como característica principal a coleta de dados diretamente com a amostra pretendida, no caso do estudo, utilizou-se o questionário com questões de múltipla escolha e abertas. Como Apêndice A apresenta a ferramenta de coleta de dados, o questionário.

\section{RESULTADOS}

Nesta seção, faz-se uma análise descritiva dos dados obtidos na pesquisa, que se referem ao perfil dos escritórios e de como os responsáveis 
estão percebendo os avanços da tecnologia em seus escritórios de contabilidade estabelecidos em Santa Catarina.

Dos questionários enviados aos 3.800 escritórios registrados em Santa Catarina, obteve-se 55 respostas distribuídas em 31 municípios catarinenses. O município de Blumenau teve o maior número de respondentes, no total de $7(13 \%)$, enquanto os municípios de Chapecó, Itajaí e Joinville tiveram 5 respondentes cada $(27 \%)$, Brusque e Florianópolis 3 respondentes $(11 \%)$, os municípios de Timbó e São José tiveram 2 respondentes (7\%), e outras 23 respostas distribuídas entre outros 23 municípios com 1 respondente $(42 \%)$.

De acordo com os dados obtidos, 27 escritórios possuem até 50 clientes e que representam $49 \%$ dos escritórios respondentes, enquanto 16 escritórios possuem entre 51 a 100 clientes representando $29 \%$ dos respondentes. Demais respondentes, no total de $12(22 \%)$ tem mais de 100 clientes. Num estudo semelhante realizado por Zwirtes e Alves (2014), o percentual de escritórios grandes, com mais de 100 clientes foi ligeiramente superior com $31,86 \%$, ao mesmo tempo que os escritórios pequenos, aqueles com menos de 50 clientes representaram $34,80 \%$ da amostra.

Quando analisado o tempo de atuação dos escritórios, pode-se observar que 24 escritórios iniciaram suas atividades nos últimos 5 anos $(44 \%), 15$ escritórios têm entre 11 a 20 anos (27\%), outros 9 tem entre 21 a 30 anos (16\%), com mais de 30 anos de atuação teve-se 7 respondentes (13\%). Zwirtes e Alves (2014) obtiveram em sua amostra no Rio Grande do Sul índices parecidos em relação tempo de atuação dos escritórios, o que faz crer que a tecnologia estimula o crescente número de novos escritórios.

Embora a tecnologia veio auxiliar nas tarefas diárias, devido a diversidade e a complexidade das atividades exigidas dos escritórios de contabilidade, não é possível a operação sem um quadro de pessoal qualificado. Entre os escritórios respondentes, a maioria (35) tem até 5 funcionários $(64 \%)$, 11 escritórios têm entre 6 a 15 funcionários (20\%), 5 escritórios têm entre 16 a 25 funcionários ( $9 \%$ ), e de 26 a 30 funcionários temos 4 respondentes $(7 \%)$.

Conforme dados extraídos no site do CFC, junto ao Conselho Regional de Contabilidade de Santa Catarina existem 3.800 organizações contábeis registradas. Destas, $2.245(59,08 \%)$ estavam registradas sob a forma de Sociedade, $661(17,39 \%)$ como empresários individuais, 577 (15,18\%) como micro empreendedores individuais (MEI) e 317 (8,34\%) como empresa individual de responsabilidade limitada (EIRELI). Entre os escritórios de Santa Catarina, pode-se observar relação percentual muito próxima aos dados oficiais do CFC. Responderam à pesquisa 31 empresas (56\%) constituídas sob a forma de Sociedade, 11 empresas (20\%) como empresários individuais, 10 (18\%) como empresas individuais de responsabilidade limitada e 3 atuam como micro empresário individual (5\%). 
Com a pesquisa, pode-se observar que $45 \%$ dos responsáveis pelos escritórios de contabilidade (25) tem Graduação, e 35\% deles (19) tem alguma especialização ou MBA, e 11\% (6) são mestres, enquanto que apenas 9\% (5) possuem a formação de técnico contábil. Entende-se de que o avanço tecnológico trazendo mais agilidade aos processos torna possível que o contador exerça seu papel, que segundo Zanluca (2009), será o conhecimento aplicado.

Observa-se que a preocupação com o conhecimento é presente entre a maioria dos respondentes.

Segundo os 21.567 registros de profissionais ativos junto ao CRCSC, $77,01 \%$ são contadores e $22,99 \%$ tem formação técnica. Na pesquisa realizada, $87 \%$ dos respondentes (48) tem a qualificação de contador e 13\% (7) atuam como técnicos em contabilidade. A comparação com os dados apresentados no parágrafo anterior, nos remete de que pelo menos 2 profissionais técnicos em contabilidade, possuem alguma graduação em outra área que não a de ciências contábeis.

Adiante, discorre-se sobre as respostas obtidas nas questões relacionadas diretamente aos impactos da tecnologia da informação junto aos responsáveis pelos escritórios localizados no estado de Santa Catarina, para as quais as respostas são de escolha entre Sim, Não, Em partes. As questões aplicadas e a tabulação das respostas obtidas podem ser visualizadas no Apêndice B.

Quando questionados se o escritório disponibiliza, remotamente, o seu banco de dados para que os clientes obtenham as informações ou relatórios que necessitam, observa-se que a maioria dos escritórios (58\%) respondentes não disponibilizam acesso em seu banco de dados para que o cliente possa consultar e emitir os relatórios dos quais necessita, enquanto que $24 \%$ dos respondentes disponibilizam dessa interação e outros $18 \%$ disseram fazê-lo em partes.

Quando questionados, se as novas obrigações acessórias, assim como o SPED Contábil, o SPED Fiscal entre outras, trouxe mais clientes, que demandavam informações a respeito das mesmas, pelas respostas obtidas observa-se que as novas exigências em relação às obrigações acessórias não foram responsáveis pelo aumento de clientes em $53 \%$ dos respondentes, e em que $29 \%$ consideram que em partes e para $18 \%$ essas novas exigências abriram portas para novos clientes.

Quando questionados se a inovação tecnológica ampliou a integração de informações do escritório para com os clientes, notou-se que para 56\% dos respondentes a inovação tecnológica foi responsável por garantir maior integração de dados dos clientes, enquanto que para $31 \%$ foi considerado que em partes e 13\% dos escritórios não sentiram esse impacto.

Quanto se a Tecnologia da Informação trouxe necessidades de melhorias contínuas na qualidade dos serviços prestados pelo escritório, evidenciou-se de acordo com $85 \%$ dos escritórios, de que a tecnologia da informação veio acompanhada da necessidade de melhorias continuas, para $9 \%$ as melhorias 
foram consideradas como necessárias em partes, e 5\% dos escritórios responderam não ser necessário.

Foram questionados também, se a Tecnologia da Informação diminuiu a quantidade de reuniões presenciais, entre o responsável pelo escritório e os clientes. Notou-se que para $42 \%$ dos escritórios, a tecnologia não dispensou a necessidade de reuniões presenciais entre o contador e o cliente, enquanto que $33 \%$ consideraram que essa necessidade diminui em partes por conta da tecnologia, e $25 \%$ responderam que a tecnologia da informação contribuiu para que a necessidade de reuniões presenciais fosse menor.

Quando questionados, se a inovação tecnológica proporcionou o crescimento do escritório em termos de número de clientes, $42 \%$ responderam que não. Já para $35 \%$ dos respondentes a tecnologia proporcionou um aumento no número de clientes, enquanto que $24 \%$ dos respondentes opinaram que isso ocorreu em partes.

De acordo com os respondentes, o escritório, com novas tecnologias, é capaz de ofertar novos produtos as seus clientes para 91\% da amostra. Outros $5 \%$ consideram que isso ocorre em partes e para $4 \%$ as novas tecnologias não influenciam para que o escritório seja capaz e oferecer novos produtos aos seus clientes.

Foram questionados também se os serviços, com apoio da TI, são agora executados com mais agilidade, e nesta questão $60 \%$ dos escritórios afirmaram que $\operatorname{sim}, 36 \%$ consideram que em partes e para $4 \%$ o apoio da TI não trouxe mais agilidade na execução dos serviços. Zwirtes e Alves (2014) identificaram que a TI gerou maior eficiência organizacional, devido a maior agilidade no compartilhamento de informações internas e externas, melhorando a qualidade dos serviços e a própria gestão do negócio.

Os serviços, com apoio da TI, são agora executados com mais segurança de acordo com $67 \%$ dos escritórios, enquanto que $24 \%$ responderam que em partes e $9 \%$ responderam que não. Quanto se a inovação tecnológica aplicada aos serviços contábeis foi um fator motivador para a criação de novos escritórios, 38\% consideram que sim, 36\% que não e $25 \%$ entendem que a inovação tecnológica motivou em partes.

Questionados se a aplicação dos sistemas de informações, aumentou o valor da média salarial dos profissionais do escritório, a resposta foi que não em $49 \%$ da amostra, que em partes para $27 \%$ e que sim para $24 \%$ das respostas. Também foi questionado, se o escritório teve a necessidade de contratar assessorias externas para dar suporte em TI, e para tal obteve-se 53\% das respostas como sim, 33\% responderam que não e $15 \%$ responderam que em partes.

Se a TI trouxe consigo maiores riscos financeiros com o desembolso de multas por atraso no envio de informações ao fisco também foi uma das perguntas, e para esta $47 \%$ responderam que sim, $44 \%$ responderam que não e 
9\% responderam que em partes. Quanto se a TI proporcionou o atendimento de novos mercados, obteve-se $45 \%$ das respostas com sim, 33\% responderam que não e $22 \%$ responderam que em partes.

Já na questão sobre se a TI proporcionou o atendimento a novas atividades, $42 \%$ responderam que sim, $31 \%$ que não em $27 \%$ que em partes. Agora, quando perguntados se a TI proporcionou maior fidelidade dos clientes para com o escritório, a maioria (53\%) responderam que não, enquanto que para $29 \%$ a resposta foi sim e para $18 \%$ em partes.

Quando a questão era se os serviços prestados pelas repartições públicas se tornaram mais ágeis com o uso da TI, $45 \%$ responderam que sim, e houve empate de $27 \%$ de respostas para não e em partes.

Em relação se com a incorporação da TI, ampliou-se a necessidade de treinamento dos funcionários para a realização dos serviços contábeis, a grande maioria ( $89 \%$ ) respondeu que sim, $9 \%$ respondeu que em partes e apenas $2 \%$ respondeu que não. Também buscou-se saber se a qualidade dos serviços prestados aumentou com o uso da TI, e nesta questão $75 \%$ dos escritórios responderam que sim, para $15 \%$ dos escritórios a resposta foi não e $11 \%$ responderam que em partes.

Muito ouve-se falar da complexidade dos diversos serviços a serem prestados pelos escritórios de contabilidade, e uma das questões foi saber se a TI causou um aumento na complexidade dos serviços prestados. E de fato, entre os respondentes, $64 \%$ responderam que sim, enquanto que houve empate com respostas para não e para em partes em $18 \%$ dos respondentes.

Nesta mesma linha, foi questionado se a TI trouxe mais tarefas ao escritório, onde $65 \%$ das respostas foram sim, $18 \%$ não e $16 \%$ em partes. Podese concluir pelas respostas obtidas nesta questão e na questão anterior, que a TI não só aumentou a complexidade como também aumentou o número de tarefas para os escritórios respondentes localizados em Santa Catarina.

Em relação a gestão do escritório, foi perguntado se esta melhorou com o uso da TI. As respostas foram que sim para $62 \%$ dos escritórios, $29 \%$ responderam que em partes e $9 \%$ responderam que não. Perguntou-se também se a comunicação interna ou externa se tornou mais ágil e eficiente com o uso da TI. As respostas afirmam que sim para $62 \%$ dos escritórios, $33 \%$ consideram que em partes e para $5 \%$ dos respondentes a resposta foi que não.

Questionou-se também se com o uso da TI houve um aumento na lucratividade do escritório, e para tal pergunta as respostas foram que não para $45 \%$ dos escritórios, para $35 \%$ em partes e $20 \%$ responderam que sim. Com isso nota-se de que a TI em si, ainda que tenha contribuído para a comunicação e para a gestão mais eficientes, a complexidade dos serviços e as novas exigências podem estar contribuindo para que a TI por si só não impacte positivamente na lucratividade dos escritórios. Zwirtes e Alves (2014) identificaram que no Rio Grande do Sul, os escritórios tiveram aumento médio da folha de 
pagamento além da necessidade de contratação de assessorias externas, gerando gastos operacionais. Além disso, o retorno dos investimentos em TI não foi proporcional ao aumento de honorários cobrados, ainda que, a TI não proporcionou diminuição do quadro de pessoal e nem mesmo contribui para o aumento de lucratividade.

A TI trouxe agilidade às informações prestadas, essa foi a afirmação a para $80 \%$ das respostas nesta questão, enquanto que $15 \%$ responderam que a TI trouxe agilidade às informações em partes, e $5 \%$ responderam que não.

Com as novas tecnologias foram surgindo novas necessidades. Muitos escritórios tiveram a necessidade de contratar profissionais mais qualificados para atender a estas necessidades. Questionados sobre isso $49 \%$ disseram que sim, que tiveram que contratar profissionais mais qualificados, $27 \%$ responderam que não e $24 \%$ responderam que em partes. Esta pode ser boa parte da resposta o porquê de mesmo com as novas tecnologias trazendo mais agilidade e eficiência aos serviços prestados, a lucratividade dos escritórios não corresponde a esta velocidade.

Outra questão não menos relevante levantada nesta pesquisa, é se os funcionários utilizam redes sociais no horário de trabalho. Houve empate para as respostas sim e não em $40 \%$, enquanto que $20 \%$ responderam que em partes. $\mathrm{O}$ uso de redes sociais no horário de trabalho é um dos fatores que pode contribuir para o aumento de custos e consequentemente menor rentabilidade para os escritórios. Zwirtes e Alves (20014) em seu estudo confirmam a preocupação dos escritórios em relação ao uso das redes sociais, que afetam a produtividade da equipe.

Buscou-se saber também se com o advento da TI ocorreu uma redução do número de funcionários do escritório. Em 73\% dos escritórios não houve redução do número de funcionários, em $15 \%$ dos escritórios sim e em $13 \%$ dos escritórios a redução correu em partes, de acordo com as respostas obtidas.

Diante deste cenário, questionou-se se o valor dos honorários aumentou de acordo com a proporção dos custos relacionados com a TI, e pode-se observar que em $67 \%$ dos escritórios isto não ocorreu, em $24 \%$ dos escritórios a resposta foi em partes e em apenas $9 \%$ houve aumento dos honorários em proporção aos custos relacionados com a TI.

E por fim, buscou-se saber se a maior inovação tecnológica para o escritório foi a vinda da internet. As respostas dizem que sim em $75 \%$ dos escritórios. Para outros 13\% a resposta foi não, igualmente 13\% para as respostas em partes.

Como síntese dessa seção, diante dos dados obtidos observa-se que são inúmeros os desafios que os escritórios contábeis ainda têm diante da inovação tecnológica, dos quais pode-se citar alguns: (i) Ampliar a Integração de informações do escritório para com os clientes; (ii) Criar meios para aumentar a fidelização de clientes, podendo-se citar o fornecimento de software de gestão 
para seus clientes, dando assessoria na implantação e treinamento do sistema, além de facilitar a parametrização e integração de dados; (iii) Treinamento constante dos profissionais; (iv) Melhorar a qualidade dos serviços prestados; (v) Otimizar as tarefas e a complexidade das mesmas; (vi) Tornar a comunicação interna e externa mais eficiente; (vii) Aumentar a lucratividade; (viii) Diminuir os custos com funcionários pelo uso abusivo das redes sociais no horário de trabalho; e (ix) Diminuir os riscos com multas por atraso ou erros na entrega de obrigações fiscais.

Espera-se que a expertise desenvolvida nas diversas atividades, sejam industriais, comerciais ou da prestação de serviços, colocando a TI como mola propulsora do desenvolvimento de produtos e serviços inovadores, também possa influenciar os serviços contábeis, especificamente dos escritórios de contabilidade.

\section{CONCLUSÃO}

A proposta do estudo é de identificar os desafios para a contabilidade interativa diante dos avanços tecnológicos, observando os escritórios contábeis localizados no estado de Santa Catarina.

Inicialmente constatou-se que os serviços contábeis vêm sofrendo adaptações constantes, forçadas pelo advento da tecnologia, mais precisamente a internet. A área contábil foi uma das que mais sofreram impactos com a introdução tecnológica, tendo que se adaptar as mudanças ocorridas nas organizações e no desenvolvimento das atividades contábeis. No entanto, é preciso que o profissional contábil tenha em mente que o processo de transformação promovido pelas inovações tecnológicas em sua atuação profissional é um processo dinâmico e contínuo. O contador assume a responsabilidade pelo gerenciamento das informações que auxilia no desenvolvimento das atividades empresarias, devendo ter consciência da sua necessidade de atualização contínua a fim de acompanhar a evolução dos procedimentos, que envolvam o fluxo das atividades da Contabilidade.

Os dados revelam inúmeros desafios, tais como o de promover a integração de dados do escritório para com os clientes, treinamento dos profissionais, a otimização das tarefas, a diminuição dos riscos com multas aplicadas pelo fisco por atraso na entrega de obrigações, melhorar a comunicação interna e a comunicação com o cliente, aumentar a lucratividade do escritório, entre tantas outras.

Por outro lado os dados também revelam oportunidades para os escritórios de contabilidade, podendo através do uso da TI ampliar as atividades atendidas, atingir novos mercados, oferecer novos produtos, disponibilizar remotamente o acesso a seu banco de dados para que os clientes consigam obter informações ou relatórios que necessitam, bem como aprofundar seus conhecimentos em gestão empresarial, atendendo a era do conhecimento 
aplicado. É preciso que empresários contábeis compreendam que a TI pode representar o diferencial do negócio, e não um fator restritivo, cuja leitura é possível compreender com a análise geral dos dados, em que se percebe que muitas das inovações ocorridas se deram porque em grande parte eram compulsórias.

Conclui-se que os principais desafios da inovação tecnológica para os escritórios é fazer uso da internet para agilizar processos de maneira segura e confiável, ao mesmo tempo que oportunidades também podem ser vistas, a exemplo da nova contabilidade, a contabilidade online, que permite ampliar o mercado de atuação.

Como todo trabalho científico, esse estudo apresenta limitações em seu desenvolvimento. Uma delas refere-se a falta de acesso aos contatos dos escritórios, que permitisse o reenvio do questionário após limitado retorno. Em relação a futuras pesquisas, os resultados sugerem outras demandas latentes: analisar como os escritórios estão se preparando para a nova forma de prestar serviços contábeis e para atender novos campos de atuação, que a tecnologia os impulsiona; identificação dos aspectos econômicos relacionados com a TI e a nova contabilidade, para que as oportunidades decorrentes possam efetivamente otimizar os processos e consequentes resultados das empresas contábeis.

\section{REFERÊNCIAS}

BANKER, R. D.; CHANG, H.; KAO, Y. Impact of Information Technology on Public Accounting Firm Productivity. Journal of Information Systems, 16 (2), 209-222, 2002.

BARBOSA, A. M. R. As implicações da tecnologia da informação na profissão contábil. XVI Congresso Brasileiro de Contabilidade, Goiânia, 2000.

CONSELHO FEDERAL DE CONTABILIDADE. Consulta nacional de ativos. Disponível em: <http://www3.cfc.org.br/spw/crcs/ConselhoRegionalAtivo.aspx>. Recuperado em 12 novembro, 2016.

CONSELHO FEDERAL DE CONTABILIDADE. Evolução anual 2011. Disponível em: <www1.cfc.org.br/uparq/Evolução_anual 2011.pdf >. Recuperado em 12 novembro, 2016.

CORNACHIONE, JR. E. B. Informática aplicada às áreas de contabilidade, administração e economia. 3. Ed. São Paulo: Atlas, 2001.

DRUCKER, P. O futuro já chegou. Revista Exame, 34 (6), 112-126, 2000.

FEDATO, G.A.L.; REHN, A.; ALMEIDA, E. I. O planejamento estratégico em empresas de serviços contábeis. Revista Contabilidade e Amazônia, 2 (1), 44-55, 2009.

HENDRIKSEN, E. S.; VAN BREDA, M. Teoria da Contabilidade. São Paulo: Atlas, 1999. 
HENRIQUE, M. A.; TADEUCCI, M. S. R.; SANTOS, I. C.; RICCI, F. Desafios na administração de empresas de serviços contábeis: da importância da profissão aos desafios atuais. Encontro Latino Americano de Iniciação Científica, São Paulo, 2009.

IUDÍCIBUS, S. D. Teoria da Contabilidade. 5. ed. São Paulo: Atlas, 1997.

IUDÍCIBUS, S. D. Teoria da Contabilidade. 6. ed. São Paulo: Atlas, 2000.

LUNELLI, R. L. A contabilidade e o avanço da tecnologia. Disponível em <http:/ / www.portaldecontabilidade.com.br/tematicas/contabilidadeetecnologia.htm $>$. Recuperado em 01 novembro, 2016.

PADOVEZE, C. L. Sistemas de informações contábeis. 2. ed. São Paulo: Atlas, 2000.

PAIVA, S. B. A Contabilidade e as novas tecnologias de informação: uma aliança estratégica. RBC, 135, 75-80, 2002.

PIRES, M. A. A.; MARQUES, V. A. Elementos estruturais da Teoria das Funções Sistemáticas. Revista de Contabilidade e Informação, 27, 3-24, 2007.

SÁ, A. L.; SÁ, A. M. L. Dicionário de Contabilidade. São Paulo: Atlas, 1995.

SCHMIDT, P. (2000). História do pensamento contábil. Porto Alegre: Bookman, 2000.

SÓ CONTABILIDADE. Biografias. Disponível em: <http:/ / www.socontabilidade. com.br/conteudo/biografia_autores.php>. Recuperado em 15 novembro, 2016.

SOUZA, T. C. G. Modelo de gestão por atividades para empresas contábeis. 135 p. Dissertação de Mestrado apresentado para o Programa de Pós-Graduação em Engenharia de Produção, Universidade Federal de Santa Catarina. Florianópolis, 2003.

SUWARDY, T.; RATNATUNGA, J.; SOHAL, A.; SPEIGHT, G. It projects: evaluation, outcomes and impediments. Emerald Benchmarking and International Journal, 10 (4), 324-342, 2003.

TIDD, J.; BESSANT, J. Gestão da inovação. 5. ed. Porto Alegre: Bookman, 2015.

TORNATZKY, L. G.; FLEISCHER, M. The processes of technological innovation. Lexington Books, 1990.

ZANLUCA, J. C. Contabilidade - Presente e futuro, Portal de Contabilidade.

Disponível em: <http:/ / www.portaldecontabilidade.com.br/tematicas / contabilidade.htm>. Recuperado em 15 abril, 2017.

ZWIRTES, A.; ALVES, T. W. Os impactos causados pela inovação tecnológica em escritórios de contabilidade do Rio Grande do Sul. Revista de Educação e Pesquisa em Contabilidade, 8 (1), 39-53, 2014. 